East African Medical Journal Vol. 86 No. 9 September 2009

AETIOLOGY OF DIARRHOEAAMONG PERSONS WITHHIV ANDTHEIR FAMILY MEMBERS IN RURALUGANDA: A COMMUNITY-BASED STUDY

J. R. Lule, MBChB, MSc, MMed, J. Mermin, MD, MPH, A. Awor, MSc, CDC-Uganda, Global AIDS Program, National Center for HIV, STD and TB Prevention, Centers for Disease Control and Prevention Uganda, P. Hughes, MSc, FIMLS, CSi, Medical Research Council Programme on AIDS in Uganda, A. Kigozi, DMLT, W. Wafula, MBChB, D. Nakanjako, MBChB, MMed, F. Kaharuza, MBChB, PhD, R. Downing, PhD, CDC Uganda, Global AIDS Program, National Centre for HIV, STD and TB Prevention, Centres for Disease Control and Prevention and R. Quick, MD MPH, Foodborne and Diarrhoeal Diseases Branch, Division of Bacterial and Mycotic Diseases, National Centre for Infectious Diseases, CDC

Request for reprints to: Dr. J. R. Lule, CDC-Uganda, Uganda Virus Research Institute, P.O. Box 49, Entebbe, Uganda

\title{
AETIOLOGY OF DIARRHOEA AMONG PERSONS WITH HIV AND THEIR FAMILY MEMBERS IN RURAL UGANDA: A COMMUNITY-BASED STUDY
}

\author{
J. R. LULE, J. MERMIN, A. AWOR, P. HUGHES, A. KIGOZI, W. WAFULA, D. NAKANJAKO, \\ F. KAHARUZA, R. DOWNING and R. QUICK
}

\begin{abstract}
Objectives: To identify pathogens associated with diarrhoea in HIV-infected persons and their HIV-uninfected family members.

Design: Prospective cohort study.

Setting: Rural community in eastern Uganda.

Subjects: Eight hundred and seventy nine HIV-infected adults $(74 \%$ females and median age 35 years (IQR, 29-41) and 2771 HIV-uninfected family members $(51 \%$ females and median age 11 years (IQR 6-16) were included.

Main outcome measures: Using microscopy and culture, stools were tested for parasites, bacteria and bacterial-antimicrobial-susceptibility. Logistic regression models, adjusting for age, $\mathrm{CD} 4$ cells, season, household clustering and use of safe-water system were used for relationships between pathogens, diarrhoea and HIV.

Results: Persons with HIV had similar pathogens in diarrhoeal $(69 \%)$ and nondiarrhoeal stools (57\%). Most diarrhoea was not associated with identifiable aetiology; the population attributable risk of diarrhoea for known diarrhoea pathogens was $32 \%$. Enteric bacteria (19\%), enteropathogenic or enterotoxigenic E. coli (8\%), Aeromonas species (7\%), Strongyloides stercoralis (8\%) and Cryptosporidium parvum (5\%). HIVinfected, stools had more Cryptosporidium parvum than HIV-uninfected (OR 2.64, 95\% CI 1.43-4.87). Most bacteria were resistant to commonly used antimicrobials irrespective of HIV status.

Conclusions: Irrespective of HIV-status, aetiologies of majority of their diarrhoea in Uganda cannot be identified by microscopy and culture. Bacterial pathogens isolated have high resistance to common antimicrobials. Empiric treatment should be tailored to local bacterial-resistance patterns.
\end{abstract}

\section{INTRODUCTION}

In sub-Saharan Africa, diarrhoea is a leading cause of morbidity in persons with HIV $(1,2)$. Previous studies of diarrhoea in persons with HIV in Africa have shown that in many cases the aetiologic agent cannot be identified $(3,4)$. The prevalence, type, and antimicrobial susceptibility of enteric pathogens isolated from stools of persons with HIV with diarrhoea exhibit variability across countries, which complicates effective empirical case management (5). To develop proper guidelines for effective empirical treatment and disease preventive practices among people with HIV, there is a need to develop a better understanding of the frequency of diarrhoea caused by specific pathogens and their susceptibility to antimicrobial agents. In addition, it is not known whether pathogens that are associated with diarrhoea among people with HIV differ from those affecting HIV-uninfected people living in the same environment. This information could be useful in the management of diarrhoea, particularly in determining whether different empiric therapy regimens should be developed depending on HIV status.

To obtain data on bacterial and parasitic pathogens associated with diarrhoea, and bacterial 
antimicrobial susceptibility patterns, we collected and tested asymptomatic and symptomatic stool specimens from people with HIV, and symptomatic stool specimens from their HIV-uninfected household members during a longitudinal intervention trial in rural Uganda. This paper describes the findings of this evaluation.

\section{MATERIALS AND METHODS}

Persons with HIV-1 infection who were clients of The AIDS Support Organisation (TASO) living in rural Tororo and Busia Districts, Uganda, without access to chlorinated municipality water were enrolled and followed-up. Enrollment consisted of two phases, identically implemented. The first from April to May 2001 and the second, from January to March 2002 (6). The study was designed to evaluate the efficacy of a safe water intervention and cotrimoxazole prophylaxis on morbidity and mortality among people with HIV and their household members. After five months of follow-up, all people with HIV began cotrimoxazole prophylaxis. Data on the safe water intervention (7) and co-trimoxazole (6) have been presented elsewhere. In this paper we include only data before participants with HIV started taking cotrimoxazole.

After written, informed consent was provided, study staff visited participants' homes to conduct a census and obtain consent from household members. Consent forms and questionnaires were translated into six local languages and back-translated into English. A household was defined as persons who shared a hearth and slept in the same house or cluster of houses for at least five days of the week for the preceding three months. A finger stick sample of blood was collected from household members on filter paper for HIV testing. All persons were encouraged to receive HIV test results and counselling at home or at the project clinic at Tororo Hospital.

At enrollment, households of persons with HIV were randomly assigned to receive either a 20-litre polyethylene vessel with a narrow mouth and a spigot (Nampak Co., Johannesburg, South Africa), one $500 \mathrm{ml}$ bottle of $0.5 \%$ sodium hypochlorite solution, a cloth for filtering water, and basic hygiene education, or education alone. Participants were interviewed about household demographic and socioeconomic characteristics, and water, hygiene, and sanitary practices. All HIV-positive participants received an assessment by a physician and provided blood samples for $\mathrm{CD} 4$ cell count enumeration and a stool sample for pathogen isolation. All participants with prevalent enteric helminths were offered treatment.
During weekly visits, study staff administered a questionnaire to all household members regarding diarrhoea episodes, days with diarrhoea, days of school or work lost and hospitalisation or death of a household member in the prior seven days. For cases of diarrhoea, defined as $\geq 3$ loose or watery stools in 24-hours, a stool specimen was collected and aliquoted. Field workers inserted two swabs into stool samples, transferred them to a tube of Cary Blair transport media, then placed one portion of stool in a tube of formal saline, and another into a sterile container for storage. All samples were placed on ice packs in a cooler, transported to the project laboratory, and refrigerated. AllCary Blair specimens were cultured within 48 hours of collection or frozen for future testing. Persons unable to provide a sample immediately were asked to insert two rectal swabs, which were immediately transferred into Cary Blair transport media, and were also given a specimen cup for a stool specimen that was retrieved later the same day. Diarrhoea was treated with oral rehydration solution and, if indicated, antimicrobial and antimotility agents. Only one stool sample was collected for each episode of diarrhoea. No patients received antiretroviral therapy, as it was not readily available in Uganda during the time of the study.

Laboratory testing: Bacteria were isolated by culture after inoculating stool samples onto blood agar, Salmonella-Shigella agar, McConkey agar and sorbitol McConkey agar and later isolation of Salmonella, Shigella, Yersinia spp., Campylobacter spp. and Escherichia coli was done using selective and differential culture media. Enrichment of Salmonella was done by inoculation of stool samples in Selenite-F broth which was incubated for 18 hours at $37^{\circ} \mathrm{C}$. This was later subcultured on S-S agar and incubated for 24 to 48 hours. The different bacteria were identified using standard biochemical methods.

For isolation of Escherichia coli, stool samples were inoculated on McConkey agar and incubated at $35-37^{\circ} \mathrm{C}$ overnight. A sweep of colonies with typical appearance of $E$. coli were taken from each plate, stored in $2 \mathrm{ml}$ of Trypticase Soy Broth with 20\% glycerol and later inoculated onto non-selective agar. After 24 hours pure E. coli colonies were used to prepare DNA suspensions which were subsequently tested by polymerase chain reaction using positive and negative DNA probe controls for identification of enteropathogenic E. coli (EPEC) and enterotoxigenic Escherichia coli (ETEC) (8). Antimicrobial resistance for bacterial stool pathogens was measured using standard, disk-diffusion techniques (9). To identify ova, cysts, and parasites from formalinised whole stool samples, the Evergreen Concentrate Kits (formalin-ethyl acetate, Faecal Parasite Concentrator, 
Evergreen Scientific, Los Angeles, CA, USA) were used, while the modified ZN stain was used toidentify Cryptosporidium and microsporidia cysts. Stool specimens were also tested for Rotavirus using the Murex Rotavirus ELISAkit(Meo-OxDiagnostics, Inc., Ottawa, Ontario, Canada). Frozen stool samples were thawed and stored for future testing for viruses.

For the index TASO clients, screening of their blood specimens for HIV infection was done using two enzyme-linked immunoassays (EIA) in parallel (Recombigen HIV-1/HIV-2, Trinity Biotech, Dublin, Ireland; and Murex HIV 120; Abbot Diagnostics, Chicago, Illinois). Specimens negative on both EIA screening tests were considered negative; specimens positive on both assays were considered positive. Specimens with discordant results were re-tested by Western Blot (LA V Blot, Biorad, Richmond, California). Dried blood spots from household members were screened for HIV using EIA (Vironostika HIV, BioMerieux, Durham, NC) and confirmation of reactive specimens by Western Blot. Polymerase chain reaction (PCR) was conducted on all HIV-reactive dried blood specimens (DBS) from children $<24$ months of age. CD4 cell counts were measured using standard procedures (FACScount; Becton- Dickinson, La Jolla, CA, Roche, New Jersey).

Data analysis and management: Data were entered using Epi Info (CDC, Atlanta, GA, USA), and analysed using SAS version 9.1 (SAS Institute, Cary, NC, USA). The proportion of stool specimens yielding enteric pathogens (defined as bacteria or parasites that are associated with enteric illness) and diarrhoeal pathogens (defined as the sub-group of enteric pathogens that have well-documented associations with diarrhoea) in the different study groups were compared using the Chi-square test. Logistic regression models were used to compare the frequency of isolation of pathogens in stool samples obtained from persons with HIV with and without diarrhoea symptoms, adjusting for differences in CD4 cell counts, age, time of year, and presence of the safe water intervention, a latrine or soap in the household. Logistic regression models were used to compare the frequency of pathogen isolation from diarrhoeal stools in persons with HIV and HIV-negative family members, adjusting for the same factors. Estimation of the population attributable risk percent (PAR\%) for enteric pathogens was calculated using previously defined methods (10).

The study protocol was approved by the Science and Ethics Committee of the Uganda Virus Research Institute, the Uganda National Council of Science and Technology, and the Institutional Review Board of the Centres for Disease Control and Prevention (CDC).

\section{RESULTS}

A total of 879 persons with HIV were enrolled, of whom $650(74 \%)$ were female. The median age was 35 years (interquartile range [IQR] 29-41 years) and 30\% had CD 4 cell counts $<200$ cells $/ \mathrm{mm}^{3}$. At baseline 562 (64\%) participants with HIV provided non-diarrhoeal stool samples that were eligible for analysis. We excluded from baseline analysis $120(14 \%)$ persons with HIV who did not provide stools samples, 185 (21\%) who had symptoms of diarrhoea within seven days of stool collection at baseline and $12(1 \%)$ who had no CD4 cell counts results. During follow-up 269 persons with HIV reported 503 episodes of diarrhoea, of which, 491 (98\%) had a stool specimen available. Of these, $62 \%$ of participants had one episode of diarrhoea, $24 \%$ had two episodes, and $14 \%$ had three or more episodes of diarrhoea during follow-up.

Of $2771 \mathrm{HIV}$-uninfected family members, the median age was 11 years (IQR 6-16 years) and 1415 $(51 \%)$ were female. Among the HIV -negative family members 229 persons had 310 episodes of diarrhoea, $303(98 \%)$ of which had an associated stool specimen available. Of these, $81 \%$ of participants had one episode of diarrhoea, $14 \%$ had two episodes, and $5 \%$ had three or more episodes. The HIV-negative family members were younger ( $p$-value $<0.0001$ ) and more likely to be male $(\mathrm{P}<0.0001)$ than persons with HIV.

At baseline $57 \%$ of stoolspecimens of persons with HIV without symptoms of diarrhoea had pathogens while $69 \%$ collected from persons with diarrhoea collected during follow-up had a pathogen, (Table 1). More than one pathogen was isolated from each of the $119(21 \%)$ asymptomatic and $138(28 \%)$ diarrhoeal stool samples of persons with HIV; and $86(28 \%)$ stool samples of persons without HIV. Of the 562 stools collected from persons with HIV, 155 (28\%) yielded one or more known diarrhoeal pathogens; of these $17 \%$ yielded bacteria, $13 \%$ Strongyloides stercoralis, and $2 \%$ yielded Cryptosporidium paroum. Stools collected during follow-up from persons with HIV with diarrhoea were more likely toyield one or moreenteric pathogens, $(69 \%$ vs. $57 \%$ adjusted odds ratio[OR] 1.63 , confidence interval [CI] 1.25-2.12; $\mathrm{p}=0.0003$ ), and as expected, more likely to yield diarrhoeal pathogens ( $51 \%$ vs. $28 \%$ adjusted odds ratio[OR] 2.69, confidence interval (CI) 2.05, 3.53; $\mathrm{p}<0.0001$ ), than asymptomatic stools collected at baseline. Several specific diarrhoeal pathogens were more frequently isolated from diarrhoeal stools than asymptomatic stools collected at baseline, these included E. coli (enteropathogenic E. coli and enterotoxigenic E. coli), Aeromonas species, Strongyloides stercoralis and Cryptosporidium parvum, (Table1). NoMicrosporidia was isolated from diarrhoeal and non-diarrhoeal stools. 
The majority of diarrhoeal episodes were not attributable to a known pathogen; and known diarrhoeal pathogens accounted for only $32 \%$ of the population attributable risk percent for diarrhoea: $19 \%$ for enteric bacteria, 8\% for E. coli, 7\% for Aeromonas species, $8 \%$ for Strongyloides stercolaris, and 5\% for Cryptosporidium parvum. Attributable risks for specific pathogens do not add to $32 \%$ due to the potential for isolation of multiple pathogens from one stool specimen. Diarrhoeal stools were less likely to yield hookworm compared to asymptomatic stools (OR) 0.73, 95\% CI, 0.55-0.97; p-value = 0.0304), (Table 1). During follow-up, pathogens were isolated in similar proportions from persons with HIV and HIV-negative family members, with the exception of Cryptosporidium parvum which was more frequent among persons with HIV (OR 2.64,95\% CI 1.43-4.87), and hookworms, which were more frequent among family members (OR 0.61 CI, 0.42-0.89, p-value $=0.01$ 12), (Table 2). Only one stool sample, from a person with HIV during follow-up, yielded rotavirus.

At CD4 cell counts $<200$ cells $/ \mu \mathrm{L}$, diarrhoeal stool samples of persons with HIV were more likely, than at CD4 counts $\geq 200$ cells $/ \mu \mathrm{L}$, to have detectable diarrhoeal pathogens (58\% vs. $49 \%$, OR $1.64,95 \%$ CI, 1.21-2.22): Cryptosporidium parvum (12\% vs. $4 \%$, OR 3.52, CI, 1.53-9.10), and Strongyloides stercoralis (24\% vs. $15 \%$, OR 2.01, CI, 1.36-2.99). We assessed for interaction between the safe water intervention and pathogens associated with diarrhoea and since we found none, we therefore combined the two study arms when presenting results.

Table 1

Pathogens isolated from stools provided by symptomatic and asymptomatic persons with HIV, Tororo and Busia Districts, Uganda*

\begin{tabular}{|c|c|c|c|c|c|c|}
\hline & $\begin{array}{l}\text { Symptomatic } \\
(\mathrm{n}=436) \\
\text { No. }(\%)\end{array}$ & $\begin{array}{l}\text { Asy } \\
(n=5 \\
\mathrm{No}\end{array}$ & $\begin{array}{l}\text { mptomatic } \\
62) \\
(\%)\end{array}$ & $\begin{array}{l}\text { Adjusted Odds } \\
\text { Ratio* }(95 \% \\
\text { Confidence } \\
\text { Interval) }\end{array}$ & P-value & $\begin{array}{l}\text { Adjusted } \\
\text { population } \\
\text { attributable } \\
\text { risk percent }\end{array}$ \\
\hline Total number of stool samples & 436 & 562 & & & & \\
\hline Enteric pathogen & 30169 & 319 & 57 & $1.63(1.25-2.12)$ & 0.0003 & \\
\hline Diarrhoeal pathogen & 22051 & 155 & 28 & $2.69(2.05-3.53)$ & $<0.0001$ & 32 \\
\hline Bacteria & 13631 & 94 & 17 & $2.46(1.82-3.32)$ & $<0.0001$ & 19 \\
\hline Campylobacter species & 9 & 11 & 2 & $1.12(0.48-2.59)$ & 0.7981 & \\
\hline Shigella species & 26 & 21 & 4 & $1.60(0.79-3.24)$ & 0.1928 & - \\
\hline Salmonella species & 16 & 18 & 3 & $0.99(0.53-1.87)$ & 0.9770 & - \\
\hline E. coli species ${ }^{* * *}$ & $75 \quad 21$ & 44 & 16 & $1.69(1.08-2.63)$ & 0.022 & 8 \\
\hline Aeromonas species & 31 & 2 & 0.4 & $20.03(4.69-85.5)$ & $<0.0001$ & 7 \\
\hline Helminths & 19545 & 266 & 47 & $0.85(0.66-1.10)$ & 0.2278 & \\
\hline Hookworms & 14032 & 225 & 40 & $0.73(0.55-0.97)$ & 0.0304 & - \\
\hline Strongyloides stercoralis & $84 \quad 19$ & 70 & 13 & $1.47(1.04-2.07)$ & 0.0290 & 8 \\
\hline Schistosoma mansoni & 15 & 12 & 2 & $1.81(0.88-3.70)$ & 0.1068 & - \\
\hline Ascaris lumbricoides & 0.5 & 1 & 0.2 & $2.59(0.23-28.6)$ & $0.4057^{1}$ & - \\
\hline Protozoa & 65 & 67 & 12 & $1.32(0.90-1.93)$ & 0.1545 & - \\
\hline Cryptosporidium parvum & 30 & 9 & 2 & $3.72(1.56-8.88)$ & 0.0031 & 5 \\
\hline Giardia lamblia & 7 & 3 & 0.5 & $2.89(0.93-8.97)$ & 0.0658 & - \\
\hline
\end{tabular}

*More than one pathogen was isolated from the same stool specimen

${ }^{* *}$ Odds Ratios and population attributable risk were adjusted for age, CD4 cell counts, presence of safe water intervention, household clustering and season, use of a latrine and washing hands with soap after visiting the latrine.

*** For the evaluation of E. coli, 353 symptomatic and 280 asymptomatic stool samples were used in the analysis.

${ }^{1}$ Fishers exact test. 
Table 2

Enteric pathogens isolated from diarrhoeal stools provided by persons with HIV and HIV-negative family members, Tororo and Busia Districts, Uganda ${ }^{+}$

\begin{tabular}{|c|c|c|c|c|c|c|}
\hline & \multicolumn{2}{|c|}{$\begin{array}{l}\text { Persons with } \\
\text { HIV } \\
(n=491)\end{array}$} & \multicolumn{2}{|c|}{$\begin{array}{l}\text { HIV-negative } \\
\text { family members } \\
(\mathrm{n}=303)\end{array}$} & \multirow{2}{*}{$\begin{array}{l}\text { Adjusted odds } \\
\text { Ratio* }(95 \% \\
\text { Confidence } \\
\text { Interval) }\end{array}$} & \multirow[t]{2}{*}{ P-value } \\
\hline & No. & $(\%)$ & No. & $(\%)$ & & \\
\hline Total Number of stools samples & 491 & & 303 & & & \\
\hline Enteric pathogen & 336 & 68 & 196 & 65 & $1.08(0.76-1.56)$ & 0.6455 \\
\hline Diarrhoeal pathogen & 246 & 50 & 140 & 46 & $1.44(1.02-2.01)$ & 0.0357 \\
\hline Bacteria & 159 & 32 & 107 & 35 & $1.27(0.87-1.86)$ & 0.2154 \\
\hline Aeromonas species & 36 & 7 & 24 & 8 & $1.07(0.54-2.10)$ & 0.8506 \\
\hline Campylobacter species & 14 & 3 & 15 & 5 & $1.25(0.48-3.31)$ & 0.6472 \\
\hline Salmonella species & 18 & 4 & 17 & 6 & $0.60(0.29-1.24)$ & 0.1688 \\
\hline Shigella species & 29 & 6 & 9 & 3 & $1.92(0.94-3.94)$ & 0.0743 \\
\hline E. coli species ${ }^{1}$ & 88 & 22 & 64 & 26 & $1.22(0.77-1.92)$ & 0.3961 \\
\hline Helminths & 213 & 43 & 113 & 37 & $0.78(0.55-1.13)$ & 0.1896 \\
\hline Strongyloides stercoralis & 90 & 18 & 36 & 12 & $1.23(0.72-2.09)$ & 0.4486 \\
\hline Hookworms ${ }^{2}$ & 154 & 31 & 97 & 32 & $0.61(0.42-0.89)$ & 0.0112 \\
\hline Protozoa & 67 & 14 & 39 & 13 & $0.98(0.60-1.59)$ & 0.9369 \\
\hline Cryptosporidium paroum & 30 & 6 & 10 & 3 & $2.64(1.43-4.87)$ & 0.0018 \\
\hline Isospora belli & 2 & 0.4 & 0 & 0 & & \\
\hline
\end{tabular}

+ More than one pathogen could be isolated from the same stool specimen.

* Odds Ratios were adjusted for age, presence of safe water intervention, household clustering and season, use of a latrine and washing hands with soap after visiting the latrine.

1 E. coli was assessed in 406 stool samples from HIV-infected persons with diarrhoea and 249 samples from HIV-negative family members with diarrhoea.

${ }^{2}$ Adults had 3.7 times more hookworms than children aged $<5$ years; (OR 3.66,95\% CI, 2.18-6.15, P-value $<0.0001)$.

Antimicrobial resistance patterns of enteric bacterial isolates: The bacterial isolates from diarrhoeal stool samples obtained during follow-up from persons with and without HIV were frequently resistant to commonly used antimicrobial agents (Table 3). No significant differences were seen in bacterial resistance to antimicrobial agents by HIV status. Resistance of
Aeromonas, Shigella, Campylobacter and E.coli species to cotrimoxazole, chloramphenicol, and ampicillin ranged from 44 to $100 \%$, while Salmonella species had lower levels of resistance to all antimicrobial agents. All bacteria were sensitive to nalidixic acid, ciprofloxacin and furazolidone with the exception of Aeromonas species (Table 3). 
Table 3

Antimicrobial resistance of enteric bacteria isolated from stool specimens from persons with HIV and their HIV uninfected household members, Tororo and Busia Districts, Uganda

\begin{tabular}{|c|c|c|c|c|c|c|c|c|}
\hline Bacteria & $\begin{array}{l}\text { HIV } \\
\text { status }\end{array}$ & $\begin{array}{c}\text { No. } \\
\text { Isolates }\end{array}$ & $\begin{array}{l}\text { Ampicillin } \\
\text { (\% resistant) }\end{array}$ & $\begin{array}{l}\text { Chloramphenicol } \\
\text { (\% resistant) }\end{array}$ & $\begin{array}{c}\text { Cotrimoxazole } \\
\text { (\% resistant) }\end{array}$ & $\begin{array}{l}\text { Nalidixic Cip } \\
\quad \text { acid } \\
(\% \text { resistant })\end{array}$ & $\begin{array}{l}\text { profloxacin } \\
\text { (\% resistant) }\end{array}$ & $\begin{array}{l}\text { Furazolidine } \\
\text { (\% resistant) }\end{array}$ \\
\hline \multirow[t]{2}{*}{ All bacteria } & Positive & 188 & 67 & 35 & 73 & 5 & 5 & 0 \\
\hline & Negative & 134 & 64 & 31 & 66 & 7 & 5 & 0 \\
\hline Aeromonas & Positive & 36 & 97 & 50 & 63 & 33 & 26 & 0 \\
\hline Species & Negative & 24 & 100 & 61 & 83 & 58 & 29 & 0 \\
\hline Shigella & Positive & 29 & 72 & 76 & 93 & 0 & 0 & NT \\
\hline Species* & Negative & 9 & 44 & 44 & 89 & 0 & 0 & NT \\
\hline Salmonella & Positive & 18 & 33 & 28 & 33 & 0 & 0 & NT \\
\hline Species* & Negative & 16 & 13 & 12 & 13 & 0 & 0 & NT \\
\hline Campylobacter & Positive & 14 & NT & NT & 92 & NT & 0 & NT \\
\hline species* & Negative & 15 & NT & NT & 100 & NT & 0 & NT \\
\hline \multirow[t]{2}{*}{ ETEC } & Positive & 52 & 56 & 14 & 85 & 0 & 0 & 0 \\
\hline & Negative & 47 & 62 & 23 & 60 & 0 & 0 & 0 \\
\hline \multirow[t]{2}{*}{ EPEC } & Positive & 36 & 61 & 28 & 69 & 0 & 0 & 0 \\
\hline & Negative & 22 & 76 & 29 & 73 & 0 & 0 & 0 \\
\hline
\end{tabular}

* Campylobacter species were not tested for sensitivity to ampicillin, chloramphenicol and furazolidone, and isolates of Shigella species and Salmonella species were not tested for sensitivity to furazolidone.

NT $=$ Not Tested.

\section{DISCUSSION}

In this longitudinal cohort of people with HIV and their HIV-uninfected family members, although diarrhoeal pathogens were identified from $69 \%$ of diarrhoeal and $57 \%$ of non-diarrhoeal stools, only $32 \%$ of diarrhoea episodes could be ascribed to an identifiable enteric pathogens. The most common pathogens associated with diarrhoea among persons with HIV were bacteria such as E. coli, Aeromonas species, Shigella, and Salmonella, and opportunistic parasites, such as Strongyloides stercoralis and Cryptosporidium parvum. The bacterial pathogens associated with diarrhoea among HIV-negative family members were also similar. The aetiology of the majority of diarrhoea occurring in persons with and without HIV in Uganda cannot be easily identified through conventional pathogen isolation measures (3, $11,12)$. It may be that non-rotavirus viral pathogens, or asyet unidentified bacteria or parasites are causing a substantial proportion of diarrhoea.

In most studies of diarrhoea among persons with $\mathrm{HIV}$, when a pathogen was isolated opportunistic infections were the major causes of diarrhoea (3, $11,13)$. However, in this study, bacteria were most frequently associated with diarrhoea, regardless of CD4 cell count. This may be due to several factors. First, we collected and processed stool specimens in the field which may have increased sensitivity for detecting bacterial pathogens; and secondly, our study was community-based, whereas most others have been clinic or hospital-associated. These differences may have enabled us to better detect pathogens associated with acute diarrhoea in comparison with other studies that may have collected stool specimens later in the course of illness, or after antimicrobial treatment had been initiated, processed samples after several hours at ambient temperature, or included more severe cases of diarrhoea that were associated with a clinic visit or hospitalisation.

There are indications that bacteria are more likely to be associated with acute diarrhoea, and opportunisticpathogens with chronic diarrhoea.Similar to previous studies, we found an association between immune suppression and Strongyloides stercoralis and Cryptosporidium parvum infection $(14,15)$.

Persons with HIV in this study had similar pathogens isolated from stools as HIV-negative family members, with the exception of Cryptosporidium parvum, Strongyloides stercoralis, and hookworms. This is similar to other studies, where pathogens from diarrhoeal stools of persons with HIV did not differ from those of persons without $\operatorname{HIV}(13,16,17)$, primarily with regard to opportunistic pathogens (11, 18). In previous analyses from this study published elsewhere, we found that episodes of diarrhoea were six times as common among HIV-infected as HIV-uninfected people, and lower CD4 cell count was associated with a threee times increased risk for diarrhoea $(6,7)$. Together, these data suggest that 
people with HIV are more likely to become ill with diarrhoea than HIV-uninfected people, but primarily with the same pathogens until their immune response is severely reduced. At that time, while they continue to develop diarrhoea from common pathogens, illness risk from opportunistic pathogens increases.

The collection of asymptomatic stool samples from persons with HIV at baseline was useful for the calculation of the population attributable risk percent. Although pathogens were isolated from $70 \%$ of diarrhoeal stools, calculation of the population attributable risk percent attributed only $32 \%$ of episodes of diarrhoea to a pathogen. Other studies have however reported higher proportion of identifiable agents from diarrhoea episodes among persons with HIV. Furthermore, pathogens are also present in the stool of people with HIV have no diarrhoea.

HIV-negative family members were more commonly infected with hookworms than HIV infected people. This is likely due to a study artifact; we collected asymptomatic stools from people with HIV at baseline and treated all people with hookworms. Thus, during follow-up, the presence of hookworms in a stool specimen from an HIVinfected participant likely represented an incident infection. This hypothesis is supported by the finding that hookworm infections were significantly more prevalent in baseline asymptomatic stools than in follow-up diarrhoeal stools in the same population of HIV positive persons. Since baseline stools were not collected from HIV-negative family members, the finding of hookworms among them during follow-up represented both prevalent and incident infection. This is also probable age confounding, since persons with HIV were adults and the HIV-negative family members mainly children, who often have higher prevalence of hookworms. Although an association between the presence of hookworms and higher CD4 cell counts among HIV-infected adults has been reported in Uganda $(19,20)$, because of these study design limitations we could not assess this question.

Antimicrobial resistance to the less expensive and most commonly used agents, such as cotrimoxazole, ampicillin, and chloramphenicol is very high in this community. However, resistance is rare to less frequently used and more expensive drugs like furazolidone, nalidixic acid and ciprofloxacin. For episodes of severe diarrhoea that require empiric treatment in this region, it would be best to avoid the drugs that have limited efficacy, especially cotrimoxazole prophylaxis which is currently recommended for all people with HIV in Uganda by the Ministry of Health. The finding that resistance patterns were similar for persons with and without HIV is encouraging, and would allow for the development of standard treatment guidelines that do not differentiate by HIV status.
This study was not able to determine the aetiological fraction for the HIV-negative family members, for comparison with that of persons with $\mathrm{HIV}$, since at baseline asymptomatic stool specimens were not collected from this population. Furthermore, this study may have underestimated E. coli in this study since there was not enough of the stool specimens for PCR for $20 \%$ of stool specimens.

In most cases of diarrhoea among persons with HIV in this community-based study in Uganda, microscopy, bacterial culture and Rotavirus testing could not identify the causative agents. For those episodes for which pathogens were isolated, there was no difference in the type of bacteria isolated between HIV-infected and uninfected persons; however, HIV-infected persons were more likely to be infected with Strongyloides stercoralis and Cryptosporidium parvum. These findings suggest that additional empiric treatment for Strongyloides stercoralis might be considered in the case of persons with HIV infection who do not respond to standard antimicrobial agents. For persons with HIV more studies are needed to determine the microbiologically detectable pathogens responsible for majority of diarrhoeal diseases among persons with HIV, which may need more improved diagnostic tests.

Funding/Support:TheHHS/CDC provided intramural funds to support the study, and staff were involved in the study design, data collection, analysis, and writing the manuscript.

\section{ACKNOWLEDGEMENTS}

We thank Tororo Hospital administrative and clinical staff; the volunteers, staff, and clients of TASO; the U.S. Embassy in Kampala; GAP headquarters; and staff of CDC-Uganda, including the informatics, clinical, laboratory, and administrative units of CDC-Tor oro, and the laboratory staff of the Medical Research Council in Uganda.

Conflict of interest statement: None of the authors had any conflicts of interest.

\section{REFERENCES}

1. Grant, A.D., et al. Profound immunosuppression across the spectrum of opportunistic disease among hospitalized HIV-infected adults in Abidjan, Cote d'Ivoire. Aids. 1997. 11: 1357-1364.

2. Chan, I.S., et al. Frequencies of opportunistic diseases prior to death among HIV-infected persons. Community Programs for Clinical Research on AIDS. Aids. 1995. 9: 1145-1151.

3. Brink, A.K., et al. Diarrhoea, CD4 counts and enteric infections in a community-based cohort of HIVinfected adults in Uganda. J. Infect. 2002. 45: 99-106. 
4. Conlon, C.P., et al. HIV-related enteropathy in Zambia: a clinical, microbiological, and histological study. Am. J. Trop. Med. Hyg. 1990; 42: 83-88.

5. Mwansa, J., et al. Antimicrobial sensitivity in enterobacteria from AIDS patients, Zambia. Emerg. Infect. Dis. 2002. 8: 92-93.

6. Mermin, J., et al. Effect of co-trimoxazole prophylaxis on morbidity, mortality, CD4-cell count, and viral load in HIV infection in rural Uganda. Lancet. 2004; 364: 1428-1434.

7. Lule,J.R., et al.Effect of home-based water chlorination and safe storage on diarrhoea among persons with human immunodeficiency virus in Uganda. Am. J. Trop. Med. Hyg. 2005. 73: 926-933.

8. Luscher, D. and Altwegg, M. Detection of shigellae, enteroinvasive and enterotoxigenic Escherichia coli using the polymerase chain reaction (PCR) in patients returningfrom tropical countries. Mol Cell Probes 1994; 8: 285-290.

9. NCCLS, Performance standardsfor antimicrobial disk and dilution susceptibility tests for bacteria isolatedfrom animals. Approved standard M31-A. National Committee for Clinical Laboratory Standards, Wayne, Pa. 1999; 19(9th international suppl).

10. Coughlin, S.S., et al., Regression methods for estimating attributable risk in population-based case-control studies: a comparison of additive and multiplicative models. Am. J. Epidemiol. 1991; 133: 305-313.

11. Fisseha B., P. B., Woldemichael, T. and Mohammed, H., Diarrhoea-associated parasitic infectious agents in AIDS patients within selected Addis Ababa Hospitals. Ethiop. J. Health Dev. 1999; 13: 169-174.

12. Mukhopadhya, A., etal., Enteric pathogensinsouthern Indian HIV-infected patients with and without diarrhoea. Indian J. Med. Res. 1999. 109: 85-89.
13. Awole, M., et al., Isolation of potential bacterial pathogens from the stool of HIV-infected and HIV-non-infected patients and their antmicrobial susceptibility patterns in Jimma Hospital, south west Ethiopia. Ethiop Med. J. 2002; 40: 353-364.

14. Wiwanitkit, V. Intestinal parasitic infections in Thai HIV-infected patients with different immunity status. BMC Gastroenterol. 2001. 1: 3.

15. Prasad, K.N., et al. Identification of enteric pathogens in HIV-positive patients with diarrhoea in northern India. J. Health Popul. Nutr. 2000; 18: 23-26.

16. Gassama, A., et al. Ordinary and opportunistic enteropathogens associated with diarrhoea in Senegalese adults in relation to human immunodeficiency virus serostatus. Int. J. Infect. Dis. 2001; 5: 192-198.

17. Lindo, I.F., etal.Intestinal parasiticinfections in human immunodeficiency virus (HIV)-positive and HIVnegative individuals in San Pedro Sula, Honduras. Am. J. Trop. Med. Hyg. 1998; 58: 431-435.

18. Fontanet, A.L., et al. Epidemiology of infections with intestinal parasites and human immunodeficiency virus (HIV) among sugar-estate residents in Ethiopia. Ann. Trop. Med. Parasitol. 2000; 94: 269-278.

19. Brown, M., et al. Screening for intestinal helminth infestation in a semi-urban cohort of HIV-infected people in Uganda: a combination of techniques may enhance diagnostic yield in the absence of multiple stool samples. Trop. Doct. 2003. 33: 72-76.

20. Brown, M., et al. Helminth infection is not associated with faster progression of HIV disease in coinfected adults in Uganda. J. Infect. Dis. 2004; 190: 18691879. 